\title{
Study on Preparation of Perforated Plate and Biofilm Colonization for Municipal Solid Waste Incineration Fly Ash
}

\author{
Jing Wang ${ }^{1}$, Chang-Jung Sun ${ }^{1, *}$, Han Liu ${ }^{1}$, Jiehua $\mathrm{Li}^{2}$ and Yan Zhang ${ }^{1}$ \\ ${ }^{1}$ Department of Environmental Engineering, City College, Dongguan University of Technology, No. \\ 1, Wenchang Road, Liaobu Town, Dongguan City, Guangdong Province, China. \\ ${ }^{2}$ Nachuan Environmental Protection Technology Co., Ltd. Address: Room 601, Unit 2, Block B, \\ Fenghua Garden, Dongtai Garden, Dongguan City, Guangdong Province, China.
}

\begin{abstract}
At present, municipal solid waste incineration (MSWI) fly ash is mainly based on the solidification agent and then landfilled. How to make the fly ash harmless and reuse it will become an important step in the circular economy. In this study, the fly ash was treated by water extraction and milling to remove the soluble chloride ions and stabilize the heavy metals, and then the perforated plate was prepared by adjusting the composition and sintering technology. Research on biofilm colonization on the perforated plates is expected to achieve the purpose of stabilizing and recycling the fly ash. The fly ash is subjected to a solid-liquid ratio of 1:5 with two-stage water extraction, $2 \mathrm{~h}$ ball milling, and then mixed at a mass ratio of waste glass powder, Palygorskite powder and the milled fly ash of $7: 2: 1$, and calcined at $850^{\circ} \mathrm{C}$ for 20 minutes to prepare perforated plate. The results show that the prepared perforated plate has a rough surface, developed internal porosity, and its water absorption rate is $19.5 \%$. The perforated plate is used as the biofilm carrier to be applied to the biological contact oxidation tank, and the natural biofilm colonization method is adopted for the 36-day biofilm culture. The average growth rate of the biofilm on the perforated plate reached $672.22 \mathrm{mg} /(\mathrm{L} \cdot \mathrm{d})$, and the maximum microbial biomass was $12.1 \mathrm{~g} / \mathrm{L}$.
\end{abstract}

\section{Introduction}

Since 2004, the amount of harmless waste incineration treatment in China has maintained rapid growth. In 2017, the amount of harmless treatment of domestic waste incineration was $84,633,200$ tons, and in 2018 , it reached $101,849,100$ tons. A large amount of the fly ash is produced in the process of municipal solid waste incineration (MSWI), and its production is about $3 \%-5 \%(\mathrm{w} / \mathrm{w})$ of the MSW amount [1]. Considering the increasing output of the municipal solid waste incineration (MSWI) fly ash and it is enriched by highly toxic heavy metals and dioxins, which will cause serious harm to the environment. Therefore, all countries in the world classify the MSWI fly ash as hazardous waste [2-4].

*Corresponding author: suncr@ccdgut.edu.cn 
The MSWI fly ash is in the form of incanus and/or dark gray powder, with lower moisture content, generally rod-like, multi-horny, cotton-like, spherical and other irregular shapes, nonuniform particle size and higher porosity and specific surface area [5-6]. The components of the fly ash are mainly $\mathrm{Si}, \mathrm{Ca}, \mathrm{Al}$, and the fraction of dissolved salts is relatively high, especially the chlorides mainly composed of $\mathrm{Ca}, \mathrm{Na}$, and $\mathrm{K}$, which are mostly as high as $37.3 \%$ [7]. The high concentration of chlorides pollutes the receiving waters during the fly ash disposal, which will increase the hazard risk of heavy metals and other pollutants, such as $\mathrm{Pb}$ and $\mathrm{Zn}$. In addition, the inorganic chloride salts will also bring difficulties for solidification/stabilization and the resource process of the fly ash. Therefore, the harm of the chlorine salt of the fly ash cannot be ignored [8]. Nowadays, the disposal technologies of the MSWI fly ash mainly include solidification/stabilization and cement kiln co-processing, etc. The mainland of China mainly adopts the treatment method of adding a chelating agent to solidification and then landfilling [9-12]. Due to the large amount of the fly ash and limited land resources, the solidification landfill treatment method is unsustainable. How to effectively harmless and resource incineration fly ash has aroused widespread concern in the field of environmental protection.

The fly ash was treated by water extraction, which could effectively remove the high concentration of dissolved salt (chloride) of the fly ash, which reduced the risk of the heavy metals released to the environment and organisms, and enhanced the product utilization value at the same time [13]. The ball milling procedure was based on the concept of Mechanochemistry Reaction, which could effectively stabilize the heavy metals of the fly ash [14]. The sintering method is an important technology for materialization, and it is a fairly mature process in the field of the material engineering, therefore it is often cited by scholars in the field of environmental engineering to recycle waste [15-16]. In this study, water extraction and ball milling were used to conduct harmless pretreatment of the fly ash. Ball milled fly ash was used as the raw material, and then completely mixed with waste glass powder and palygorskite for roasting to prepare perforated plates. The perforated plate was applied to the biological contact oxidation process to study its biofilm colonization performance.

\section{Materials and methods}

\subsection{Materials}

The materials used in this study can be divided into three parts: MSWI fly ash, waste glass and palygorskite. The fly ash (raw fly ash) was collected from an MSWI located in Shenzhen. Its color is incanus. The raw fly ash was sealed and placed on a flip-type oscillator at a rotation speed of $50 \mathrm{rpm}$ and mixed evenly for use. The waste glass was taken to a waste recycling station in Dongguan, the color is transparent, and it would be crushed, ground, and then passed through a 200-mesh standard sieve (with a particle size of $0.075 \mathrm{~mm}$ ) for use. Palygorskite was in a non-purified state, and it passed through an 800 mesh standard sieve (with a particle size of $0.018 \mathrm{~mm}$ ) for future use.

\subsection{Apparatus mold}

Horizontal axis ball mill: used to stabilize heavy metals in the fly ash. Agitation apparatus : used for the operation of the Toxicity Characteristic Leaching Procedure (TCLP) of heavy metals of the fly ash. Atomic Absorption Spectrophotometer (AAS): used for the determination of heavy metals of the fly ash. Scanning Electron Microscope (SEM): used for the microstructure observation of the fly ash. Analytical balance: used for weighing 
experimental materials. Research-grade microscope: used for observation of biological phases in biofilm. Furnace: used for roasting in the perforated plates. Tablet press: used for press forming of perforate plates green body. Biological contact oxidation tank: used for biofilm culture of perforated plates.

\subsection{Methods}

This was a two-stage process with a water/solid ratio of 5; the extraction time was 5 min for each stage. After the mixed fly ash passes through the water-extraction process it is called extracted fly ash. And then the concentration of heavy metals and chloride ions were measured. The milled fly ash undergone toxicity leaching experiment to determine the concentration of heavy metals of the leaching solution by adopting the "Solid waste leaching toxicity leaching method-Acetic acid buffer solution method" (HJ/T 300-2007) Three materials of waste glass powder, palygorskite and the milled fly ash were mixed with a ratio of 7:2:1 and then the perforated plate was sintered. The preparation process is as follows:

Adjustment $\rightarrow$ Mixing $\rightarrow$ Compression molding $\rightarrow$ Drying $\rightarrow$ Sintering $\rightarrow$ Perforated plates

\section{Results and discussion}

\subsection{The Characteristics of the MSWI Fly Ash}

The compositions of the raw fly ash and the extracted fly ash are shown in Table 1 . The concentrations of heavy metals of the raw fly ash and of the leaching solution, as shown in Table 2, the experimental data show that the leaching concentration of lead in the raw ash reaches $4.62 \mathrm{mg} / \mathrm{L}$, which could cause serious environmental pollution. The highest contents of heavy metals are $\mathrm{Zn}$ and $\mathrm{Pb}$. This phenomena are the same as the distribution of the fly ash emissions from waste incinerator in southern China [4]. Therefore, the raw fly ash needs to be pretreated by water extraction and ball milling.

Table 1. The compositions composition of the raw fly ash and the water extracted fly ash.

\begin{tabular}{cccccccc}
\hline Sample & $\mathrm{Ca}$ & $\mathrm{K}$ & $\mathrm{Na}$ & $\mathrm{Al}$ & $\mathrm{Mg}$ & $\mathrm{Fe}$ & $\mathrm{Ti}$ \\
\hline $\begin{array}{c}\text { Raw fly ash } \\
(\%)\end{array}$ & $36.6 \pm 0.46$ & $2.89 \pm 0.07$ & $2.36 \pm 0.08$ & $1.35 \pm 0.13$ & $1.01 \pm 0.04$ & $0.82 \pm 0.02$ & $0.05 \pm 0.01$ \\
$\begin{array}{c}\text { Water } \\
\text { extracted fly } \\
\text { ash (\%) }\end{array}$ & $34.7 \pm 0.25$ & $0.13 \pm 0.03$ & $0.30 \pm 0.04$ & $1.46 \pm 0.17$ & $1.16 \pm 0.04$ & $0.92 \pm 0.03$ & $0.02 \pm 0.00$ \\
\hline
\end{tabular}


Table 2. The concentrations of heavy metals of the raw fly ash and of the leaching solution.

\begin{tabular}{cccccc}
\hline Sample & $\mathrm{Pb}$ & $\mathrm{Cd}$ & $\mathrm{Cr}$ & $\mathrm{Cu}$ & $\mathrm{Zn}$ \\
\hline $\begin{array}{c}\text { Concentration of the raw fly } \\
\text { ash (mg/kg) }\end{array}$ & 683 & 226 & 98 & 93 & 2412 \\
$\begin{array}{c}\text { Concentration of the } \\
\text { leaching solution }(\mathrm{mg} / \mathrm{L})\end{array}$ & 4.62 & $\mathrm{ND}^{*}$ & 0.28 & 0.023 & 0.82 \\
\hline
\end{tabular}

* ND: Not detectable.

\subsection{Optimization of water extraction and milling process}

\subsubsection{Effect of water extraction}

The fly ash contains a large amount of soluble chloride salts, and these characteristics are not conducive to reuse the fly ash. Table 1 shows that the proportions of potassium and sodium removed by water extraction are obvious, the contents of potassium and sodium are from $2.89 \%$ and $2.36 \%$ to $0.13 \%$ and $0.3 \%$, which shows that water extraction can effectively remove soluble potassium and sodium. After the two-stage water extraction, the concentration of heavy metals of the raw fly ash also changed, as shown in Figure 1.

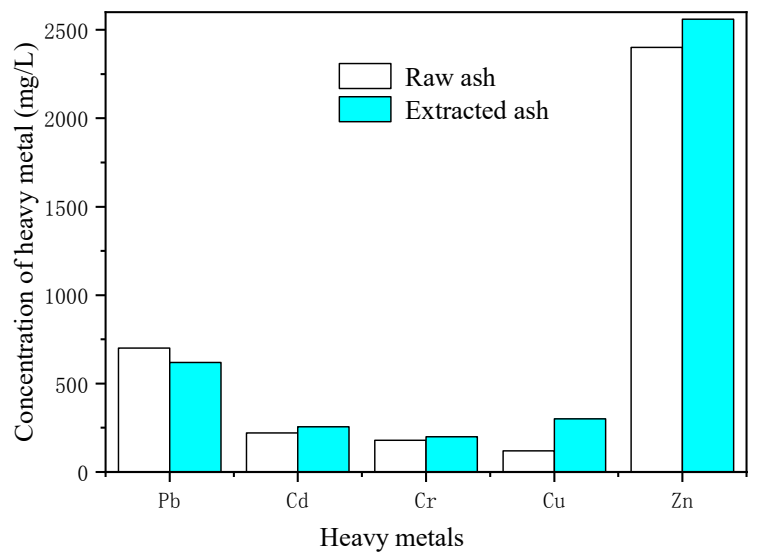

Figure 1. The Concentration of the heavy metal of the raw fly ash and the water extracted fly ash.

The experimental results show that water extraction conditions with different solidliquid ratios, the chloride concentration of the supernatant decreased as the solid-liquid ratio increased, as shown in Figure 2(a). In order to further explore the dissolution of soluble chloride in the fly ash, the study selected the conditions of solid-liquid ratio of 1:5, and after multiple water extractions, the concentration of chloride in the supernatant was determined. As shown in Figure 2(b), after the two-stage water extraction, the chloride concentration of the water extraction solution was effectively reduced. After the water extraction to the third times, the chloride ion concentration drop in the water extraction solution was slowed down. 

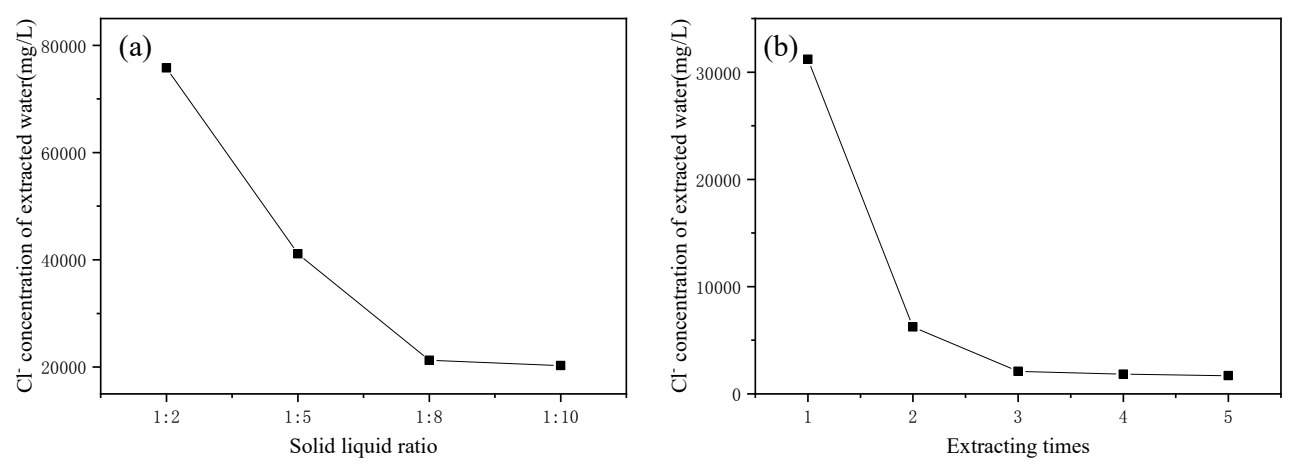

Figure 2. The concentration of chloride in the different water extraction conditions with (a) different solid-liquid ratios; (b) different water extraction times.

\subsubsection{Effect of milling treatment on stabilizing heavy metals}

The water extracted fly ash was dried and weighed and then ball milled. The prepared ball milled fly ash was subjected to toxicity leaching experiment using "Solid Waste Leaching Toxicity Leaching Method-Acetic Acid Buffer Solution Method" (HJ/T 300-2007). The experimental results show that after $1 \mathrm{~h}$ ball milling, the heavy metal leaching concentration is significantly reduced, as shown in Table 3. Continue to extend the milling time, the leaching concentration of lead and zinc further reduced and then fell below the detection limit, as shown in Figure 3(a) and (b). Moreover, the effect of the stabilization of the heavy metals is better than the SDD and TEPA-DTC chelating agent [17]. The leaching concentration of the heavy metals of the milled ash was significantly reduced because the longer milling time, the denser the particle agglomerates formed, and the heavy metals are sealed in the milled ash and cannot be effectively leached, thereby making the heavy metals into the milled ash. In addition to ball milling has the effect of stabilizing heavy metals, ball milled ash may also have the function of storing energy [3], which is worthy of further study.

Table 3. The concentration of the heavy metals of the water extracted fly ash, and the concentration of the heavy metal in leaching solution of the water extracted fly ash and the milled ash of $1 \mathrm{~h}$ milling.

\begin{tabular}{cccccc}
\hline Items & $\mathrm{Pb}$ & $\mathrm{Cd}$ & $\mathrm{Cr}$ & $\mathrm{Cu}$ & $\mathrm{Zn}$ \\
\hline $\begin{array}{c}\text { The concentration of the heavy metals of } \\
\text { the water extracted fly ash }(\mathrm{mg} / \mathrm{kg})\end{array}$ & 605 & 226 & 98 & 358 & 2511 \\
$\begin{array}{c}\text { The concentration of the heavy metals in } \\
\text { leaching solution of the water extracted } \\
\text { fly ash }(\mathrm{mg} / \mathrm{L})\end{array}$ & 1.8 & $\mathrm{ND} *$ & $\mathrm{ND}$ & $\mathrm{ND}$ & 0.65 \\
$\begin{array}{c}\text { The concentration of the heavy metals in } \\
\text { leaching solution of the milled ash(mg/L) }\end{array}$ & 0.65 & $\mathrm{ND}$ & $\mathrm{ND}$ & $\mathrm{ND}$ & 0.24 \\
$\quad$ Regulatory Level (mg/L) & 0.25 & 0.15 & 4.5 & 40 & 100 \\
\hline
\end{tabular}

* ND: Not detectable 

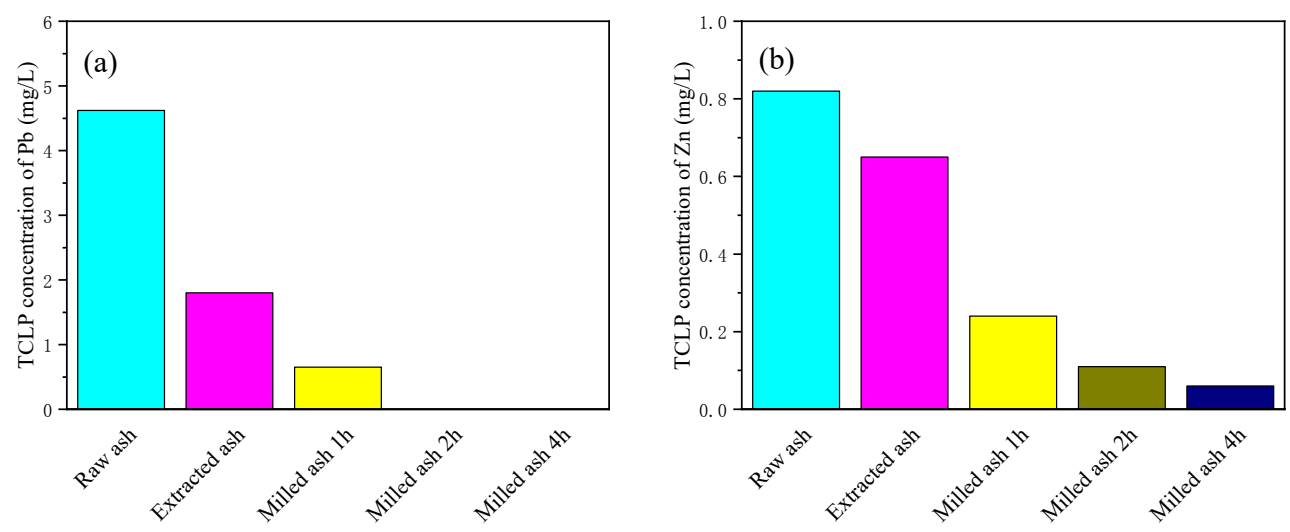

Figure 3. Leaching content of heavy metal of milled ash during different milling time (a) $\mathrm{Pb}$; (b) Zn.

\subsubsection{The characteristics of the biofilm colonization of perforated plate}

Setting 32 perforated plates $\left(\mathrm{L}^{*} \mathrm{~W}=50 \mathrm{~mm} * 50 \mathrm{~mm}\right.$, as shown in Figure $4(\mathrm{a})$ ) in the biological contact oxidation tank device, with 16 plates on each layer, and 2 layers in total. The bottom of the tank is aerated and fed, and the upper part is discharged. The biofilm cultivation is added nutrients according to the ratio of carbon: nitrogen: phosphorus $=100$ : $5: 1$ and no seeding during the whole 36 days of the cultivation time.

On the 4th day of the biofilm formation, a light-yellow bright film grew on the perforated plate. The microscopic examination showed that there were fewer microorganisms at this time, mainly linear mycelium, and a small amount of protists, as shown in Figure 4 (b) and (c). On the 12th day of the biofilm formation, a gray-brown biofilm with a thickness of about $1-2 \mathrm{~mm}$ has been attached to the perforated plate. The microscopic examination results show that there were more protozoa (paramecium) attached to it and grow, as shown in Figure 4 (d) and (e). On the 18th day of biofilm formation, the biofilm on the perforated plate further thickened to $2-3 \mathrm{~mm}$, and the color of the biofilm changed to a certain extent. The outermost layer was khaki, and the bottom was dark brown. The microscopic examination showed that a large number of metazoans appeared, such as rotifers, as shown in Figure 4(f). 

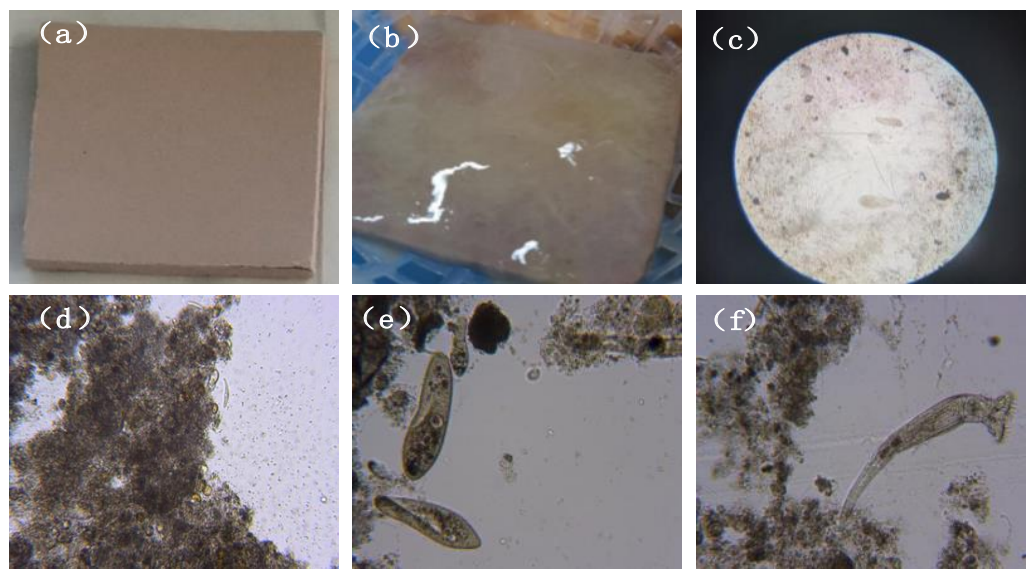

Figure 4. The appearance of the perforated plate and microscopic examination of the microbial phase on different days before and after the culture time (a) the appearance of the raw perforated plate ; (b) the appearance of the biofilm after 4 days; (c) the microstructure of the biofilm on the 4th day; (d) The microstructure of the biofilm on the 12th day; (e) the microbial phase (paramecium) on the 12th day; (f) the microbial phase (rotifer) on the 18th day.

Starting from the initial formation of the biofilm, the amount of biofilm on the perforated plate was measured per 6 days. As shown in Figure 5, from the beginning of culture to 18 days, the biofilm grew faster, and the amount of biofilm continued to increase to $12.1 \mathrm{~g} / \mathrm{L}$. When the biofilm was cultured to 18 days, the biofilm had matured and gradually started aging and falling off, therefore the amount of biofilm has decreased. The aging biofilm is constantly falling off and growing. Therefore, the amount of biofilm is maintained in the range of $4.64-8.28 \mathrm{~g} / \mathrm{L}$, and the average growth rate of biofilm is $672.22 \mathrm{mg} /(\mathrm{L} \cdot \mathrm{d})$.

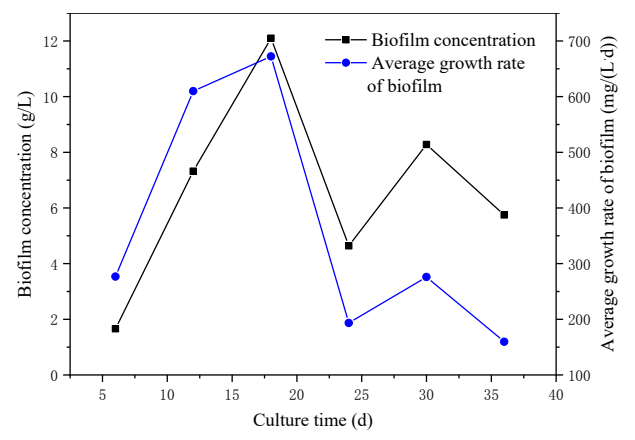

Figure 5. Changes of biofilm amount and growth rate during different culture time.

\section{Conclusion}

The MSWI fly ash adopts a solid-liquid ratio of 1:5, and the soluble chloride salt can be effectively removed through two-stage water extractions. The concentration of chloride ions of the extracted water was reduced from $31,196 \mathrm{mg} / \mathrm{L}$ to $6,239 \mathrm{mg} / \mathrm{L}$ during the extraction process. The potassium and sodium content are also reduced respectively from $2.89 \%$ and $2.36 \%$ to $0.13 \%$ and $0.3 \%$ in the extraction process. The heavy metals could be stabilized in the water extracted fly ash during the milling process, and the leaching concentrations of the heavy metals can meet the limit of "Identification Standards for 
Hazardous Wastes-Identification of Leaching Toxicity". The ratio of waste glass powder, palygorskite and milled fly ash is $7: 2: 1$, and after sintering at $850^{\circ} \mathrm{C}$ for 20 minutes, a perforated plate is prepared with a water absorption rate of $19.5 \%$. The perforated plate is used as a biofilm carrier in a biological contact oxidation tank. Method for biofilm culture, the maturation period of biofilm is about 18 days, the maximum amount of biofilm can reach $12.1 \mathrm{~g} / \mathrm{L}$, and the average growth rate of biofilm can reach $672.22 \mathrm{mg} /(\mathrm{L} \cdot \mathrm{d})$.

\section{Acknowledgement}

The authors would like to thank the City College of Dongguan University of Technology and Dongguan Science and Technology Bureau, for their financial support of this research (2019YZDYB01Z; 2020QJY008Z; 2020507151152).

\section{References}

[1] X. G. Jiang, W. Chang. Journal of Zhejiang University of Technology, 43(1), 7-17, (2015)

[2] S. S. Dong. Guangxi light industry, 58 (9), 104-105, (2009)

[3] S. S. Jahromy, C. Jordan, M. Azam, et al. Energ Fuel, 33(JUL.), 5810-5819, (2019)

[4] P. Wang, Y. Hu, H. Cheng. Environ Pollut, 252(Part A), 461-475, (2019)

[5] X. J. Ma. Hangzhou: Zhejiang University, (2013)

[6] L. Y. Song,. Shanghai: East China University of Science and Technology, (2010)

[7] F. F. Zhu, C. H. Gaogang, K. Oshita. Environmental Science, 34(6), 2473-2478, (2013)

[8] Y. S. Ling, J. Y. Jin, Y. F. Nie. Environmental Protection Science, 38(4), 1-5, (2012)

[9] H. P. Xiao, Y. Ru, L. Li. Research of Environmental Sciences, 30(2), 291-297, (2017)

[10] Y. SU, J. YANG, D. LIU. J Environ Chem Eng, 1, 259-265, (2016)

[11] Y. Xu, Y. Chen, Y. Y. Feng. CIESC Journal, 64(5), 1833-1839, (2013)

[12] J. B. Wang, R. X. Qin. Environmental Science \& Technology, 36(9), 139-143, (2013)

[13]R. Yong, W. Liao , P. Wu. J Environ Manage, 104, 67-76, (2012)

[14] M. G. Li, C. J. Sun, S. H. Gau, C. J. Chuang. J Hazard Mater, 174, 586-591, (2010)

[15] K. S. Wang, K. Y. Chiang, J. K. Perng, C. J. Sun. J Hazard Mater, 59, 201-210, (1998)

[16] C. J. Sun, M. G. Li, S. H. Gau, Y. H. Wang, Y. L. Jan. J Hazard Mater, 195, 281-290, (2011)

[17] M. Zhang, M. Guo, B. Zhang, et al. Waste Manage, 105, 289-298, (2020) 